\title{
Sanguinello and Tarocco (Citrus sinensis [L.] Osbeck): Bioactive compounds and colour appearance of blood oranges
}

\author{
Laura Cebadera-Miranda ${ }^{\mathrm{a}}$, Laura Domínguez ${ }^{\mathrm{a}}$, Maria Inês Dias ${ }^{\mathrm{b}}$, Lillian Barros ${ }^{\mathrm{b}}$, \\ Isabel C.F.R. Ferreira ${ }^{\mathrm{b}}$, Marta Igual ${ }^{\mathrm{c}}$, Nuria Martínez-Navarrete ${ }^{\mathrm{c}}$, Virginia Fernández-Ruiz ${ }^{\mathrm{a}}$, \\ Patricia Morales $^{\mathrm{a}}$, Montaña Cámara ${ }^{\mathrm{a}, *}$ \\ a Department Nutrition and Food Science, Faculty of Pharmacy, Complutense University of Madrid (UCM), Plaza Ramón y Cajal, s/n, E-28040 Madrid, Spain \\ ${ }^{b}$ Centro de Investigação de Montanha (CIMO), Instituto Politécnico de Bragança, Campus de Santa Apolónia, 5300-253 Bragança, Portugal \\ ${ }^{\mathrm{c}}$ Universitat Politècnica de València, Food Technology Department, Food Investigation and Innovation Group, Camino de Vera s/n, 46022 Valencia, Spain
}

\section{A R T I C L E I N F O}

\section{Keywords:}

Sanguinello

Tarocco

Blood oranges

Anthocyanins

Flavonoids

Organoleptic quality

\begin{abstract}
A B S T R A C T
Sanguinello and Tarocco (Citrus sinensis [L.] Osbeck) are the most common and widespread blood oranges varieties in the Mediterranean climate area. Its interest is increasing mainly due to nutritional and organoleptic properties. In this work, three blood orange varieties cultivated in Spain (Sanguinelli, Tarocco Rosso and Tarocco Ippolito) were characterized in relation to physicochemical parameters and relevant bioactive compounds (vitamin C, organic acids, flavonoids and anthocyanins) as well as colour characterization. All samples showed important vitamin $\mathrm{C}$ values (higher than $54.9 \mathrm{mg} / 100 \mathrm{~g}$ of edible portion). Flavonoids represent the largest family of phenolic compounds, being hesperidin, the major flavonoid. Ten different anthocyanins were identified in blood oranges, seven cyanidin derivatives and three delphinidin derivatives, being the most abundant cyanidin 3-(6"-malonylglucoside) and cyanidin 3-glucoside. Blood oranges can show an intense reddish colour in peel whereas the pulp has a yellow-orange colour. Overall, these varieties are good sources of bioactive compounds.
\end{abstract}

\section{Introduction}

Blood oranges are the result of a spontaneous genetic mutation that occurred many centuries ago in plants native from China, due to the migratory movements throughout the Mediterranean. It has been cultivated in Sicily since the fifteenth century. Although the original plantation of lemons and bitter oranges in Sicily is attributed to the Arabs, it was the Genovese and Portuguese crusaders who introduced the sweet variety, becoming a basic element of the Sicilian kitchen and receiving even the quality denomination of Protected Geographical Indication (PGI) (Barreca, Gattuso, Laganà, Leuzzi, \& Bellocco, 2016).

Sanguinello and Tarocco (Citrus sinensis [L.] Osbeck) are the most common and widespread blood oranges varieties in the Mediterranean climate area, mainly southern Italy and Spain (in Europe), and most recently in California (United States of America). These varieties are consumed worldwide in both, fresh and processed products such as fruit juices (Kelebek, Canbas, \& Selli, 2008).

Spain has a long tradition in citriculture that began probably in the 7th century (Agustí, 2003). Nowadays Spanish oranges quality is recognized globally due to its good organoleptic properties. Spain is the main citrus producing country in Europe; with orange production in 2017 reaching 3.4 million tons (FAOSTAT, 2017), most of which are exported in the European markets (MAPAMA, 2017). Although the production of blood orange varieties in Spain is limited, its interest is increasing in the recent years mainly due to its nutritional and organoleptic properties (bright colour and pleasant taste).

Considering the importance of citrus production in Spain, the main objective of the present study is to identify and quantify the bioactive compounds present in Sanguinello and Tarocco blood orange varieties, Citrus sinensis [L.] Osbeck as well as to evaluate their colour as a relevant parameter for consumer acceptance.

\section{Materials and methods}

\subsection{Samples}

Three varieties of blood oranges (Citrus sinensis (L.) Obsbeck) cultivated in the region of Valencia (Comunidad Valenciana, Spain) were

\footnotetext{
* Corresponding author.

E-mail address: mcamara@ucm.es (M. Cámara).
} 
considered for study: Sanguinelli (Citrus sinensis (L.) cv. Sanguinelli), which comes from an spontaneous mutation of blood orange Doble Fina (C. sinensis L. cv. Double Fine) that was firstly detected in 1929 in Almenara (Castellón, Spain); Tarocco Rosso and Tarocco Ippolito (Citrus sinensis (L.) cv. Tarocco).

In Spain, due to environmental conditions, blood oranges commercial consumption stage goes from middle of January to the end of March. Samples considered in this study were harvested during 2015 season. Three different batches were collected at very beginning, middle and later period, providing a representative sample of fruits offered to consumers at commercial consumption stage.

Prior analysis, the peel was separated from the pulp. Fresh pulp was homogenized (Ultraturrax ${ }^{\circledast}$ ). Aliquots of the homogenized pulp were used for physico-chemical determinations (moisture, $\mathrm{pH}$ and titratable acidity), as well as for the determination of vitamin C.

Another portion of homogenized fresh pulp was subjected to freeze drying process. Lyophilized fresh pulp was ground and homogenized, stored in airtight containers, in the dark, at $-20^{\circ} \mathrm{C}$, in order to avoid product alteration.

\subsection{Chemical characterization}

\subsubsection{Physico-chemical parameters}

Moisture, $\mathrm{pH}$, titratable acidity and grades Brix were determined according to official methods (Horwitz \& Latimer, 2005) in homogenized oranges fresh pulp.

Ripeness index was calculated by the ${ }^{\circ} \mathrm{Brix} / \mathrm{TA}$ ratio, with TA being titratable acidity expressed as $\mathrm{mg}$ of citric acid/100 $\mathrm{g}$ of fruit edible portion.

The colorimetric characterization of the blood oranges studied was determined by tri-stimulus colorimetric method based on the CIELAB parameters $\left(\mathrm{L}^{*}, \mathrm{a}^{*}, \mathrm{~b}^{*}, \mathrm{C}^{*}\right.$ and hue) using Hunter Color Flex Colorimeter, with the following specifications: CIE illuminant $\mathrm{C}$, and $45^{\circ} / 0^{\circ}$ geometry. The coordinates that define the colour of the sample are: the photometric index $\left(\mathrm{L}^{*}\right)$ which varies between 0 (black) and 100 (white); $a$ and $b$ values which range from -100 to +100 , being $+a^{*}$ depending on the intensity of the red colour, $-a^{*}$ depending on the intensity of the green colour, $+b^{*}$ depending on the intensity of the yellow colour and $-b^{*}$ depending on the intensity of the blue colour. Chroma $\left(C^{*}\right)$ is the quantitative colorfulness attribute as it determines the difference degree in comparison to a grey colour with the same lightness for each hue (CIE, 2001). Hue angle (h) is a parameter that defines the colors traditionally as pinkish, yellowish and greenish. $\mathrm{C}^{*} \mathrm{ab}$ and hue angle $\left(h_{a b}\right)$ was calculated following the Eqs. (1) and (2), respectively:

$\mathrm{C}_{\mathrm{ab}}^{*}=$ saturation index $\left(\mathrm{a}^{* 2}+\mathrm{b}^{* 2}\right)^{1 / 2}$

$\mathrm{h}_{\mathrm{ab}}=1 / \tan \left(b^{*} / a^{*}\right)$

These colour parameters CIELAB were measured in the homogenized pulp and in the peel. The pulp sample was placed in cylindrical glass cuvettes measuring $5 \mathrm{~cm}$ in diameter and $1.3 \mathrm{~cm}$ in height. External fruit colour was evaluated by three consecutive measurements of three different parts of the fruit: the darkest part of peel, the clearest part and the base of the piece of fresh fruit.

\subsubsection{Vitamin $C$ and organic acid content}

The extraction of vitamin $C$ and organic acids was carried out in acid medium (Sánchez-Mata et al., 2012) and analyzed and quantified by high performance liquid chromatography (HPLC) in reverse phase with UV-visible detection (Thermo Separation Spectra Series UV100). The equipment consists in an isocratic pump (model PU-II), an AS-1555 automatic injector (Jasco, Japan), a Sphereclone ODS (2) $250 \times 4.60$, $5 \mu \mathrm{m}$ Phenomenex column, and a UV-visible detector (Thermo Separation Spectra Series UV100, Madrid, Spain). The mobile phase was $1.8 \mathrm{mM} \mathrm{H}_{2} \mathrm{SO}_{4}(\mathrm{pH}=2.6)$. For AA analysis a flow-rate of $0.9 \mathrm{~mL} / \mathrm{min}$ and UV detection at $245 \mathrm{~nm}$ was used, while conditions for organic acids were $0.4 \mathrm{~mL} / \mathrm{min}$ and at $215 \mathrm{~nm}$. The identification was perform using Biocrom 2000 3.0. Software by comparison of the retention times of each chromatographic peak with those of standards products. Values were expressed as $\mathrm{mg} / 100 \mathrm{~g}$ of fruits edible.

\subsubsection{Carotenoids content: $\beta$-carotene and lycopene}

Standards of all-translycopene and $\beta$-carotene used in this work were from Sigma-Aldrich-Fluka (St. Louis, MO), with a purity of $90 \%$. For identification and quantification purposes, individual working standard solutions were daily prepared by dilution in hexane (Merk, Darmstadt, Germany).

Carotenoids analysis in blood oranges was carried out after extraction by a hexane:acetone:methanol solvent $(50: 25: 25 v / v / v)$ by spectrophotometry of the hexane layer, according to Olives Barba et al. (2006). A Pharmacia Ultrospec 4000 UV/vis spectrophotometer was employed for absorbance measurements (at $446 \mathrm{~nm}$ for $\beta$-carotene and $502 \mathrm{~nm}$ for lycopene) using quartz cells of path length $1 \mathrm{~cm}$.

\subsubsection{Phenolic compounds}

2.2.4.1. Non anthocyanin flavonoids. The extraction and chemical characterization of flavonoids was carried out following the procedure proposed by Igual, García-Martínez, Camacho, and Martínez-Navarrete (2011). The flavonoids were characterized by high performance liquid chromatography (HPLC) couple to UV-visible detector (MD-1510, Jascos, Italy) with a range of measurement wavelength of $190-650 \mathrm{~nm}$, with a ternary pump (Jasco PU-1580 HPLC pump), a gradient generator (LG-1580-02 Ternary Gradient Unit) and Ultrabase-C18 column $(5 \mu \mathrm{m}, 4.6 \times 250 \mathrm{~mm})$. The mobile phase was composed of (A) methanol and (B) water and a linear gradient elution was performed starting at 30:70 to reach 100:0 at $70 \mathrm{~min}$, with a flow rate of $1 \mathrm{~mL} / \mathrm{min}$. Chromatograms were recorded at 286,284 and $254 \mathrm{~nm}$ and at $25^{\circ} \mathrm{C}$. The standard curves of the reference flavonoids, narirutin (NAT), naringin (NAR), hesperidin (HES), neohesperidin (NEOH), didymin (DID), poncirin (PON), naringenin (NAG) and quercetin (QUER) (Extrasynthese, France) were used to quantify the flavonoids. Naphthalene was used as internal standard. Values were expressed as $\mathrm{mg} / 100 \mathrm{~g}$ per edible portion.

\subsubsection{Anthocyanins}

Sample extraction and characterization was performed following the procedure described by Gonçalves et al. (2017). Double detection was carried out by DAD, using $520 \mathrm{~nm}$ as the preferred wavelength, and in a MS connected to the HPLC system via the DAD cell outlet. Anthocyanins were tentatively identified by comparing their UV-vis and mass spectra with available standards and data in our compound library and the literature. For quantitative analysis, a calibration curve for each available phenolic standard was constructed based on the UV signal: cyanidin-3-O-glucoside ( $\left.\mathrm{y}=630.276 \mathrm{x} 153.83 ; R^{2}=0.999\right)$ and delphinidine-3-O-glucoside $\left(\mathrm{y}=557.274 \mathrm{x}+126.24 ; R^{2}=0.999\right)$. The results were expressed in $\mathrm{mg} / 100 \mathrm{~g}$ of edible portion.

\subsection{Statistical analysis}

Results were expressed as means of a minimum of triplicate analyses $(\mathrm{n}=3)$ and corresponding standard deviations. Analysis of variance (ANOVA) using Tukey's test was applied to analyse data at the $95 \%$ confidence level.

\section{Results and discussion}

\subsection{Physico-chemical parameters}

Results corresponding to the characterization of the blood oranges samples in terms of moisture, ${ }^{\circ} \mathrm{Brix}$, titratable acidity, $\mathrm{pH}$ and ripeness index is shown in Table 1.

The average moisture contents for three blood oranges analyzed 
Table 1

Physicochemical parameters (moisture, pH, TA, ${ }^{\circ}$ Brix and Ripeness index, RI) evaluated in Citrus sinensis [L.] Osbeck varieties.

\begin{tabular}{|c|c|c|c|c|c|c|}
\hline Variety & Batch & Moisture (g/100 g) & $\mathrm{pH}$ & TA & ${ }^{\circ}$ Brix & RI \\
\hline \multirow[t]{3}{*}{ Sanguinelli } & A & $82.21 \pm 0.75 a$ & $3.05 \pm 0.01 \mathrm{a}$ & $14.69 \pm 0.23 b$ & $13.33 \pm 0.15 a$ & $14.53 \pm 0.65 a$ \\
\hline & B & $87.49 \pm 0.08 c$ & $3.52 \pm 0.04 c$ & $13.65 \pm 0.47 a$ & $14.33 \pm 0.06 b$ & $16.42 \pm 0.52 b$ \\
\hline & $\mathrm{C}$ & $85.70 \pm 0.06 b$ & $3.27 \pm 0.01 b$ & $13.59 \pm 0.52 \mathrm{a}$ & $14.63 \pm 0.06 c$ & $16.84 \pm 0.62 b$ \\
\hline Range of Variation: & & $81.46-87.57$ & $3.04-3.56$ & $13.07-14.92$ & $13.18-14.69$ & $13.88-17.46$ \\
\hline \multirow[t]{3}{*}{ T. Rosso } & A & $79.96 \pm 0.22 \mathrm{a}$ & $2.95 \pm 0.01 \mathrm{a}$ & $16.36 \pm 0.06 b$ & $13.53 \pm 0.21 \mathrm{a}$ & $13 \cdot 10 \pm 0,48 a$ \\
\hline & B & $85.76 \pm 0.01 b$ & $3.52 \pm 0.01 c$ & $13.73 \pm 0.20 \mathrm{a}$ & $13.77 \pm 0.12 \mathrm{a}$ & $15.48 \pm 0,49 b$ \\
\hline & $\mathrm{C}$ & $85.59 \pm 0.17 b$ & $3.35 \pm 0.01 b$ & $13.42 \pm 0.34 \mathrm{a}$ & $15.20 \pm 0.10 \mathrm{~b}$ & $17.70 \pm 0,34 \mathrm{c}$ \\
\hline Range of Variation: & & 79.74-85.77 & $2.94-3.53$ & $13.08-16.42$ & $13.32-15.30$ & $12.62-18.04$ \\
\hline \multirow[t]{3}{*}{ T. Ippolito } & A & $81.12 \pm 0.27 a$ & $3.07 \pm 0.02 \mathrm{a}$ & $12.78 \pm 0.23 b$ & $14.13 \pm 0.06 \mathrm{~b}$ & $17.28 \pm 0.27 \mathrm{a}$ \\
\hline & B & $87.46 \pm 0.04 c$ & $3.75 \pm 0.01 c$ & $11.27 \pm 0.09 \mathrm{a}$ & $12.63 \pm 0.06 a$ & $18.91 \pm 0.16 b$ \\
\hline & $\mathrm{C}$ & $85.45 \pm 0.11 b$ & $3.67 \pm 0.02 b$ & $11.65 \pm 0.29 a$ & $14.73 \pm 0.12 c$ & $19.76 \pm 0.68 c$ \\
\hline Range of Variation: & & $80.85-87.50$ & $3.05-3.76$ & $11.18-13.01$ & $12.57-14.85$ & $17.01-20.44$ \\
\hline
\end{tabular}

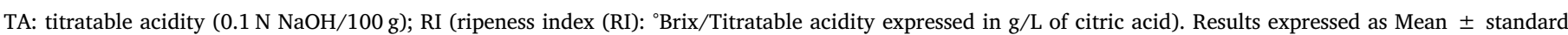

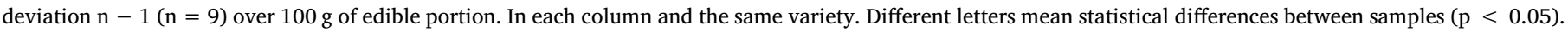

during the 2015 season range from 79.74 to $87.57 \mathrm{~g} / 100 \mathrm{~g}$ of edible portion. The range of $\mathrm{pH}$ values in the samples of blood oranges studied was between 2.95 and 3.67 (Tarocco Rosso and Tarocco Ippolito, respectively, Table 1), highlighting the variety Tarocco Ippolito. These results are similar to other blood orange varieties such as Moro and T. Messina varieties both from Italy (Rapisarda, Lo Bianco, Pannuzzo, \& Timpanaro, 2008) and Moro and Sanguinello varieties from Turkey (Kelebek et al., 2008).

All varieties of blood oranges studied showed similar and homogeneous values for soluble solids content. These data are similar with those indicated by other authors such as Kelebek (2008) for Moro $\left(12.0^{\circ}\right.$ Brix) and Sanguinello $\left(12.6^{\circ} \mathrm{Brix}\right)$; and similar values (range: 11.3-13.53) to those described by other authors (Abdelaali et al., 2018; Continellaa et al., 2018).

Ripening index (RI) values, calculated as ${ }^{\circ} \mathrm{Brix} / \mathrm{TA}$, and expressed in grams of citric acid per $100 \mathrm{~mL}$, are similar in all samples analyzed. These values are slightly higher than those described by other authors for other blood oranges varieties, such as Tarocco Scirè (10.5-13.9) according to Continellaa et al. (2018).

\subsection{Vitamin $C$ and organic acids}

Vitamin C was calculated as the sum of ascorbic and dehydroascorbic acids in the varieties of blood oranges (Table 2). In general, all studied samples shown high concentrations of vitamin C content, highlighting the Sanguinelli and Tarocco Rosso varieties ( 66.70 and $66.42 \mathrm{mg} / 100 \mathrm{~g}$, respectively). Regulation (EU) No 1169/ 2011, related to consumer information on food labelling, indicates a nutrient reference value (NRV) for vitamin C of $80 \mathrm{mg} /$ day. According to this regulation, we can assert that the consumption of $100 \mathrm{~g}$ of blood oranges pulp would cover at least $68 \%$ of these recommendations, and in all cases, these oranges may be promoted as a natural source of vitamin C, covering more than $15 \%$ of such recommendations.

As the amounts of dehydroascorbic acid found in the samples were insignificant (traces), in the following table (Table 2) only the results for ascorbic acid are shown. The AA values obtained are in agreement with those reported for Tarocco and Moro varieties, 53.3 and $66.9 \mathrm{mg} /$ $100 \mathrm{~mL}$ of juice, respectively (Arena, Fallico, \& Maccarone, 2001) and T. Messina and T. Meli (55.37-64.77 mg/100 mL of juice, respectively, Rapisarda et al., 2008). Results obtained in the present study were much higher than those indicated by other authors for other varieties of blood orange, such as Cara Cara and Moro Blood (34.24-31.83 mg/ 100 g, respectively; Kafkas, Ercisli, Kemal, Baydar, \& Yilmaz, 2009).

In relation to the other organic acids, oxalic, tartaric, malic, ascorbic, citric and fumaric acids were characterized in the studied orange fruits (Table 2). It's well know that fruits undergo important

Table 2

Organic acids and vitamin C content in Citrus sinensis [L.] Osbeck varieties (mg/100 g per edible portion).

\begin{tabular}{|c|c|c|c|c|c|c|c|}
\hline Variety & Batch & Oxalic acid & Tartaric acid & Malic acid & Citric acid & Fumaric acid & Vitamin C \\
\hline \multirow[t]{3}{*}{ Sanguinelli } & $\mathrm{A}$ & $6.28 \pm 0.62 \mathrm{a}$ & $48.96 \pm 4.61 \mathrm{a}$ & $137.84 \pm 1.25 \mathrm{a}$ & $1020.33 \pm 7.03 a$ & $0.71 \pm 0.03 b$ & $54.94 \pm 0.08 a$ \\
\hline & B & $17.06 \pm 2.22 \mathrm{~b}$ & $72.67 \pm 2.43 b$ & $132.25 \pm 9.62 \mathrm{a}$ & $1138.41 \pm 49.07 b$ & $0.23 \pm 0.02 \mathrm{a}$ & $56.05 \pm 0.91 \mathrm{a}$ \\
\hline & $\mathrm{C}$ & $8.50 \pm 2.48 a$ & $92.44 \pm 2.10 c$ & $126.28 \pm 11.31 \mathrm{a}$ & $1622.70 \pm 83.09 c$ & $0.20 \pm 0.03 a$ & $66.70 \pm 0.56 b$ \\
\hline Range of variation: & & $5.66-26.17$ & $44.35-94.54$ & 114.97-139.09 & $1013.30-1705.79$ & $0.17-0.74$ & $54.86-67.26$ \\
\hline \multirow[t]{3}{*}{ T. Rosso } & $\mathrm{A}$ & $8.61 \pm 0.84 a$ & $44.75 \pm 3.47 a$ & $159.32 \pm 2.94 b$ & $1236.82 \pm 29.14 a$ & $0.52 \pm 0.07$ & $59.11 \pm 0.66 a$ \\
\hline & B & $10.57 \pm 2.05 a$ & $68.95 \pm 5.35 b$ & $78.92 \pm 2.33 a$ & $1169.64 \pm 56.29 a$ & $\operatorname{tr}$ & $65.49 \pm 0.35 b$ \\
\hline & $\mathrm{C}$ & $7.56 \pm 0.34 a$ & $86.75 \pm 6.81 c$ & $163.07 \pm 8.28 b$ & $1592.82 \pm 25.05 b$ & $0.17 \pm 0.01$ & $66.42 \pm 0.54 b$ \\
\hline Range of variation: & & $7.22-12.62$ & $41.28-93.56$ & 76.59-171.35 & $1113.35-1617.87$ & $\operatorname{tr}-0.59$ & $58.45-66.96$ \\
\hline \multirow[t]{3}{*}{ T. Ippolito } & A & $17.38 \pm 1.77 a$ & $35.88 \pm 1.23 \mathrm{a}$ & $122.89 \pm 6.55 a$ & $979.38 \pm 7.14 b$ & $0.64 \pm 0.13 b$ & $57.32 \pm 0.29 b$ \\
\hline & $\mathrm{B}$ & $18.01 \pm 7.81 \mathrm{a}$ & $64.95 \pm 2.45 b$ & $116.35 \pm 15.83 a$ & $864.99 \pm 10.17 a$ & $0.18 \pm 0.11 \mathrm{a}$ & $55.06 \pm 0.34 a$ \\
\hline & $\mathrm{C}$ & $15.45 \pm 3.37 a$ & $89.01 \pm 4.93 c$ & $241.52 \pm 10.12 b$ & $1236.31 \pm 26.26 c$ & $0.29 \pm 0.05 a$ & $59.17 \pm 0.47 c$ \\
\hline Range of variation: & & $12.08-25.82$ & $34.65-93.94$ & $100.52-251.64$ & $854.82-1262.57$ & $0.07-0.77$ & $54.72-59.64$ \\
\hline
\end{tabular}

tr: traces $(<0.01 \mathrm{mg} / 100 \mathrm{~g} \mathrm{ssf})$. Results expressed as mean \pm standard deviation $\mathrm{n}-1(\mathrm{n}=9)$. In each column, the different letters indicate statistically significant differences $(\mathrm{p}<0.05)$ between batches for each variety. In each column and the same variety, different letters mean statistical differences between samples $(\mathrm{p}<0.05)$. 
changes during maturation process strongly affect to organic acid profile as well as other related parameters. Organic acids tend to decrease with maturation of the fruit, mostly because of the use of these compounds as respiratory substrates, as well as, for new substances synthesis. Also it is important to highlight that the difference organic acid profile and amount between samples from different origins may be related to different environmental conditions, since organic acid profile is extremely conditioned by climate conditions (López-Bucio, NietoJacobo, Ramírez-Rodríguez, \& Herrera-Estrella, 2000).

Blood oranges studied were noted for their high content of citric acid, which is the major organic acid, with values ranging from 864.99 to $1622.70 \mathrm{mg} / 100 \mathrm{~g}$ in Tarocco Ippolito and Sanguinelli, respectively (Table 2), being the Tarocco Rosso variety the one with the highest average content. Other authors analyzed the citric acid content in similar varieties of blood oranges, obtained values of 1130 and $1340 \mathrm{mg} /$ $100 \mathrm{~mL}$ of juice for Moro and Sanguinello varieties, respectively (Kelebek, 2008), data that agree with those obtained in the current study. These values for the content of this organic acid were much higher than other varieties of blood oranges analyzed by other authors, such as the Cara Cara and Moro Blood varieties $(421-561 \mathrm{mg} / 100 \mathrm{~mL}$ of juice respectively, Kafkas et al., 2009). The following major organic acids in all analyzed blood oranges were malic and tartaric acids. This content did not show a large difference between varieties, which is in concordance with authors (Braverman, 1933; Vandercook, 1977). Fumaric acid was the minor organic acid in all blood oranges analyzed, other authors also reported that fumaric acid values in this type of citrus fruits were very low and even impossible to quantify (Lee, Carter, Barros, Dezman, \& Castle, 1990).

\subsection{Carotenoids content}

Traditionally it has been considered that the major carotenoids in oranges were violaxanthin, anteraxanthin, lutein, $\alpha$-cryptoxanthin, $\beta$ cryptoxanthin, $\alpha$-carotene and $\beta$-carotene, however, more recent studies have revealed that some of them were mistakenly identified (Meléndez-Martínez et al., 2005, 2008). An exceptional accumulation of lycopene in some citrus fruits has been evidenced in orange and grapefruit mutants, as in Cara Cara, mutant of the Navel orange (Citrus sinensis [L]. Osbeck) (Alquézar, Rodrigo, \& Zacarias, 2008) and Hong Anliu, mutant of Anliu (Citrus sinensis [L]. Osbeck) (Liu, Liu, \& Tao, 2006), derived from work done by the National Laboratory for Genetic Improvement of Crops, Huazhong Agricultural University and Citrus Research Institute, RP China.

Results obtained in this study indicate that $\beta$-carotene was present in the blood oranges considered in this study. This is in agreement with the work carried out at the Institute of Agrochemistry and Food Technology (IATA) in Valencia and the Spanish Scientific Research Council (CSIC) by Alquézar, Zacarías, and Rodrigo (2009) that indicate the general absence of carotenoid lycopene in citrus fruits.

All varieties analyzed showed similar and homogeneous values of $\beta$ carotene content (Table 3). Among the blood oranges samples, Tarocco Ippolito stands out because it presented the highest average value $(0.542 \mathrm{mg} / 100 \mathrm{~g})$, while the Tarocco Rosso variety had the lowest $\beta$ carotene content $(0.261 \mathrm{mg} / 100 \mathrm{~g})$, with statistically significant differences $(\mathrm{p}<0.05)$ between varieties.

\subsection{Phenolic compounds}

Tarocco Ippolito was the variety with the highest total flavonoid content, whereas Tarocco Rosso presented the lowest value (statistically significant differences, $\mathrm{p}<0.05$ ). Comparing our results with those obtained by other authors, the total content of flavonoids was higher than those reported by Lee et al. (1990), which indicated values for a type of blood orange (California) of $68-88 \mathrm{mg} / 100 \mathrm{~mL}$ of juice. In general, the total content of flavonoids is higher than that of other citrus fruits such as grapefruit $(141 \mathrm{mg} / 100 \mathrm{~g}$ according to Igual, García-
Martínez, Camacho, and Martínez-Navarrete (2013)). The identified flavonoids in the studied blood oranges were: narirutine, hesperidin, naringin, didimine, quercetin and naringenin according to Kelebek et al. (2008) and Berhow, Tisserat, Kanes, and Vandercook (1998). Table 3 shows the results for the main flavonoids identified and quantified from the different standard curves used. The most abundant flavonoid in the studied blood oranges was hesperidin (values ranging from 78 to $143 \mathrm{mg} / 100 \mathrm{~g}$ in Tarocco Rosso and Sanguinelli, respectively). Tarocco Ippolito and Sanguinelli varieties showed the highest content (range from 99.9 to $119.0 \mathrm{mg} / 100 \mathrm{~g}$ and 92.9 to $143 \mathrm{mg} / 100 \mathrm{~g}$, respectively). The next major flavonoid was narirutine $(37.0-93.0 \mathrm{mg} /$ $100 \mathrm{~g}$ edible portion, followed byquercetin $(28.1-42 \mathrm{mg} / 100 \mathrm{~g}$ edible portion). Tarocco Ippolito variety showed the highest value of narirutine (variation range of $60.9-93.0 \mathrm{mg} / 100 \mathrm{~g}$ ) in relation to the other analyzed oranges. Sanguinelli was the variety that presented the highest content of quercetin. On the other hand, naringenin was the minor flavonoid in all varieties studied.

In a study conducted by Barreca et al. (2016), the blood oranges Sanguinello and Tarocco presented a similar profile that obtained in the current study. Hesperidin was the major flavonoid, obtaining values for Sanguinello and Tarocco of 42.6 and $10.6 \mathrm{mg} / 100 \mathrm{~mL}$ of juice, respectively, followed by narirutin values of $6.1 \mathrm{mg} / 100 \mathrm{~mL}$ of juice for Sanguinello and $1.4 \mathrm{mg} / 100 \mathrm{~mL}$ in Tarocco. These results are much lower than those obtained in the blood oranges considered in the present work.

Regarding anthocyanin compounds, the peak characteristics (retention time, $\lambda_{\max }$ in the visible region, mass spectral data) and tentative identification and quantification of anthocyanin compounds in Tarocco samples are present in Table 4 . Ten compounds were identified in all samples, seven cyanidin derivatives (peaks 2, 3, 5, 6, 7, 9, and 10) and three delphinidins derivatives (peaks 1, 4 and 8). Peaks 1, 2, 3, 4, 6,7 and 9 were previously identified by other authors in blood orange samples (Destani, Cassano, Fazio, Vincken, \& Gabriele, 2013; Dugo, Mondello, Morabito, \& Dugo, 2003; Fabroni, Ballistreri, Amenta, \& Rapisarda, 2016; Hillebrand, Schwarz, \& Winterhalter, 2004; Kelebek et al., 2008; Lee, 2002). All the compounds were identified according with their MS characteristics (molecular ion and MSn fragmentation pattern), UV spectra and where tentatively identified comparing this data with information reported in the literature. Nonetheless, compounds 5,8 and 10 , to the best of our knowledge, were not previously described in orange blood samples. Peak $\mathbf{5}$ was tentatively identified as a cyanidin (malonyl) diglucoside, presenting a pseudomolecular ion [M $+\mathrm{H}]^{-}$at $m / z 697$, releasing a unique $\mathrm{MS}^{2}$ fragment at $m / z 287$ ([M $+\mathrm{H}-410]^{-}$, which might correspond to the joint successive loss of a malonyl group $(-86 \mathrm{mu})$ and two glucoside units $(-324 \mathrm{mu})$. Peak 8 was tentatively identified as delphinidin-3-rhamnoside, presenting a pseudomolecular ion $[\mathrm{M}+\mathrm{H}]^{-}$at $m / z 449$ and a unique $\mathrm{MS}^{2}$ fragment at $m / z 303$ (delphinidin aglycone) corresponding to the loss of a rhamnoside unit $\left([\mathrm{M}+\mathrm{H}-146]^{-}\right.$. Peak 10 showed a pseudomolecular ion $[\mathrm{M}+\mathrm{H}]^{-}$at $m / z 679$ and a $\mathrm{MS}^{2}$ fragment at $m / z 287([\mathrm{M}+\mathrm{H}-$ $392]^{-}$, which might correspond to the successive loss of a malonyl $(-86 \mathrm{mu})$, dioxalyl $(-144 \mathrm{mu})$ and hexoside $(-162 \mathrm{mu})$ units, being tentatively identified as cyanidin malonyl-(dioxalyl)-hexoside. Dugo et al. (2003) reported the presence of a similar compound in blood orange fruit juice, however it only identifies the aglycone (cyanidin).

In general, all varieties studied showed high values in the individual content of each of the identified compounds, as well as the total content of anthocyanins. All Spanish blood oranges studied showed similar and homogeneous values in the total anthocyanins content, all of which showed values in the range of $6.95-25.26 \mu \mathrm{g} / 100 \mathrm{~g}$ of edible portion. Sanguinelli sample presented the highest concentration of anthocyanin compounds $(25.26 \mu \mathrm{g} / 100 \mathrm{~g}$ edible portion), mainly due to peaks 3 (cyanidin 3-glucoside) and 6 (cyanidin 3-(6"-malonyl) glucoside). The most abundant peak in all samples was peak 6 (cyanidin 3-(6"-malonyl) glucoside), followed by peak 3 (cyanidin 3-glucoside). Of course, the three blood oranges Sanguinelli, Tarocco Rosso and Tarocco Ippolito 
Table 3

Content of major flavonoids and $\beta$-carotene present in Citrus sinensis [L.] Osbeck varieties (mg/100 g per edible portion).

\begin{tabular}{|c|c|c|c|c|c|c|c|}
\hline Variety & Batch & Narirutine & Hesperidin & Naringenin & Quercetin & Total flavonoids & $\beta$-carotene \\
\hline \multirow[t]{3}{*}{ Sanguinelli } & A & $57.4 \pm 1.0 \mathrm{~b}$ & $97.0 \pm 4.1 \mathrm{a}$ & $1.04 \pm 0.0 \mathrm{c}$ & $37.9 \pm 1.4 \mathrm{~b}$ & $193.0 \pm 6.0 \mathrm{~b}$ & $0.418 \pm 0.086 a$ \\
\hline & B & $60.4 \pm 1.2 c$ & $140.0 \pm 3.0 c$ & $0.94 \pm 0.0 \mathrm{~b}$ & $40.0 \pm 2.0 \mathrm{~b}$ & $241.0 \pm 7.0 c$ & $0.366 \pm 0.022 \mathrm{a}$ \\
\hline & $\mathrm{C}$ & $41.1 \pm 4.1 \mathrm{a}$ & $111.0 \pm 2.0 \mathrm{~b}$ & $0.48 \pm 0.1 \mathrm{a}$ & $29.4 \pm 1.3 a$ & $182.0 \pm 1.0 \mathrm{a}$ & $0.381 \pm 0.015 a$ \\
\hline Range of variation: & & $37.0-65.6$ & 92.9-143.0 & $0.47-1.04$ & $28.1-42.0$ & $181.0-248.0$ & $0.366-0.418$ \\
\hline \multirow[t]{3}{*}{ T. Rosso } & A & $53.1 \pm 2.0 \mathrm{c}$ & $96.0 \pm 2.1 b$ & $1.00 \pm 0.4 a$ & $31.8 \pm 0.4 a$ & $181.0 \pm 0.0 \mathrm{a}$ & $0.295 \pm 0.023 a$ \\
\hline & B & $41.0 \pm 3.0 \mathrm{a}$ & $100.0 \pm 6.1 b$ & $1.42 \pm 0.0 \mathrm{~b}$ & $36.0 \pm 3.0 \mathrm{~b}$ & $178.0 \pm 12.0 \mathrm{a}$ & $0.261 \pm 0.082 \mathrm{a}$ \\
\hline & $\mathrm{C}$ & $46.9 \pm 0.7 b$ & $84.0 \pm 6.0 \mathrm{a}$ & nd & $35.9 \pm 1.0 \mathrm{~b}$ & $166.0 \pm 5.1 \mathrm{a}$ & $0.386 \pm 0.077 \mathrm{a}$ \\
\hline Range of variation: & & $37.0-55.1$ & $78.0-106.1$ & nd-1.42 & $31.4-39.0$ & $160.9-181.0$ & $0.261-0.386$ \\
\hline \multirow[t]{3}{*}{ T. Ippolito } & A & $62.0 \pm 1.1 \mathrm{a}$ & $104.0 \pm 4.1 \mathrm{a}$ & $2.4 \pm 0.3 b$ & $38.0 \pm 3.0 \mathrm{a}$ & $209.0 \pm 9.0 \mathrm{a}$ & $0.588 \pm 0.055 \mathrm{a}$ \\
\hline & B & $91.0 \pm 2.0 \mathrm{c}$ & $116.0 \pm 3.0 \mathrm{~b}$ & $1.08 \pm 0.1 \mathrm{a}$ & $38.8 \pm 0.7 a$ & $258.0 \pm 7.0 \mathrm{~b}$ & $0.487 \pm 0.050 \mathrm{a}$ \\
\hline & $\mathrm{C}$ & $68.2 \pm 0.4 \mathrm{~b}$ & $106.4 \pm 0.5 a$ & $1.07 \pm 0.1 \mathrm{a}$ & $39.7 \pm 0.5 \mathrm{a}$ & $216.0 \pm 1.0 \mathrm{a}$ & $0.550 \pm 0.035 \mathrm{a}$ \\
\hline Range of variation: & & $60.9-93.0$ & $99.9-119.0$ & $1.06-2.07$ & $35.0-40.2$ & $200.0-265.0$ & $0.487-0.588$ \\
\hline
\end{tabular}

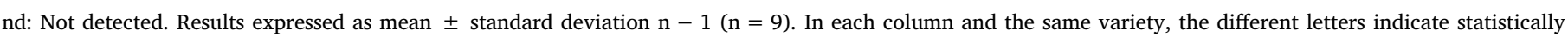
significant differences $(\mathrm{p}<0.05)$ between batches for each variety.

showed the highest content of both compounds, ranging from 2.75 to $10.85 \mu \mathrm{g} / 100 \mathrm{~g}$ of edible portion of cyanidin 3-(6"-malonyl) glucoside (major compound) and $2.32-8.18 \mu \mathrm{g} / 100 \mathrm{~g}$ of cyanidin-3-glucoside edible portion. This anthocyanins profile corresponds to that described by other authors for similar varieties (Tarocco and Sanguinello) from Italy (Barreca et al., 2016), California (Lee, 2002). It also corresponds to other varieties of blood oranges from China (Liang, Shao-Qian, \& Si-Yi, 2011). On the other hand, Barbagallo, Palmeri, Fabiano, Rapisarda, and Spagna (2007) published a study analyzing the anthocyanins content in Taroccos from Italy (15.6 and $11.5 \mathrm{mg} / 100 \mathrm{~mL}$ juice). Liang et al. (2011) also conducted a study on Taroccos from China, which showed that the majority anthocyanins in this type of fruit are cyanidin 3-(6"malonyl) glucoside and cyanidin-3-glucoside, as reflected in the present study (Shao-Qian, Si-Yi, Xiao-Lian, \& Hong-Fei, 2010).

\subsection{Colour characterization. Study of correlations between pigments and colour measurement}

Appearance, including fruit colour, is generally used as a selection criterion throughout the supply and consumer chain. The intensity of the pigmentation depends on several factors such as: variety, soil type, climate, weather conditions of the campaign, etc. For example, warm summers followed by cold winters produce fruits of more intense pigmentation. Peel and pulp colour is not uniform, and it does not always correspond to a blood zone of the peel with red pulp below that zone. This more coloured area usually appears in the part of the fruit with north orientation (Kafkas et al., 2009).

As the accumulation of lycopene is quite unusual in this type of oranges, and lycopene has not been identified in samples analyzed, the characteristic red colour of blood oranges should be attributed to a combination of $\beta$-carotene and anthocyanic compounds (Barreca et al., 2016; Rapisarda, Bellomo, \& Intrigliolo, 2001).

The instrumental measurement of blood orange colour by the analysis of CIELAB colour parameters ( $\mathrm{L}^{*}, \mathrm{a}^{*}, \mathrm{~b}^{*}, \mathrm{C}^{*}$ and hue) can give an estimation of its pigments content as carotenoids and anthocyanins (Meléndez-Martínez, Gómez-Robledo, Melgosa, Vicario, \& Heredia, 2011).

Regarding the pulp colour parameters (Table 5), Tarocco Rosso variety showed the lowest values of parameter a* (lower intensity of red colour) and the highest $b^{*}$ values (higher intensity of yellow-orange colour). The profiles of $\mathrm{L}^{*}$ (brightness) and hue parameter, show the same behaviour with $\mathrm{a}^{*}$ and $\mathrm{b}^{*}$ parameters, being Tarocco Rosso, the variety with the highest values while the others two varieties analyzed showed lower and similar levels between them. Regarding saturation index C, all samples studied showed similar levels. In general, the colour parameters obtained show variations, but not deviate from the values mentioned by other authors for other citrus varieties (Choi, Kima, \& Leeb, 2002). Such variation may be due to the characteristics of the product, the selected variety and the time of harvesting.

In order to evaluate if the selected colour parameters are predictive values of the pigment content of the analyzed samples, a study of the correlations between the different CIELAB parameters $\left(\mathrm{L}^{*}, \mathrm{a}^{*}, \mathrm{~b}^{*}, \mathrm{C}^{*}\right.$ and h) of the pulp and the pigment content, carotenoid and anthocyanin compounds were carried out (Table 6). Correlation study shows that all colour parameters are strongly correlated with both, total anthocyanin content and $\beta$-carotene content in the pulp. As expected, the parameter $\mathrm{a}^{*}$ showed positive correlation with the content of these compounds ( 0.613 and 0.709 for $\beta$-carotene and total anthocyanins content, respectively), since this parameter is the one that measures the intensity of the orange-reddish colour, characteristic colour of these pigments.

On the other hand, the parameters $\mathrm{L}^{*}, \mathrm{~b}^{*}$, chroma $\mathrm{C}^{*}$ and hue, show a strong negative correlation with the total content of $\beta$-carotene and anthocyanins. It means that the colour fruits with a tendency to yellow and away from red, along with a more vivid and clear colour, could indicate a lower content of these pigments. Nevertheless, $\beta$-carotene showed no significant correlation $(\mathrm{p}>0.05)$ with the parameter $\mathrm{C}^{*}$.

Regarding to peel colour of samples analyzed (Table 6), the parameter $\mathrm{a}^{*}$ show similar values for all varieties studied in a reduced range (27.16-39.10). These values for the $\mathrm{a}^{*}$ parameter are close to those found in the pulp. However, the parameter $b^{*}$ together with the brightness and saturation index $\mathrm{C}^{*}$ profiles showed the lowest value for the Sanguinelli variety, which means that Sanguinelli variety show in their peel a redder colour than the other peel samples analyzed. In this sense, no direct relationship was found between the external and internal coloration of these fruits studied. It was observed that the peel follows a different behavior to the pulp. In view of the results, it can be found varieties with an intense yellow-orange coloration (higher parameter $\mathrm{b}^{*}$ ) and reddest pulp (higher parameter $\mathrm{a}^{*}$ ), as it happens in the Tarocco Ippolito variety and alternatively, it can be found varieties with a more reddish coloration on their peel, and more yellow-orange pulp, as in the case of Tarocco Rosso variety.

\section{Conclusions}

We can affirm that the blood oranges Sanguinelli and Tarocco Rosso are good sources of vitamin C and could cover the $100 \%$ of nutrient reference value (NRV). Cítric acid is the predominant organic acid. Tarocco Ippolito variety showed the highest $\beta$-carotene and total flavonoid content. The predominant flavonoid in the studied oranges was hesperidin being Sanguinelli the variety with the highest content of this 


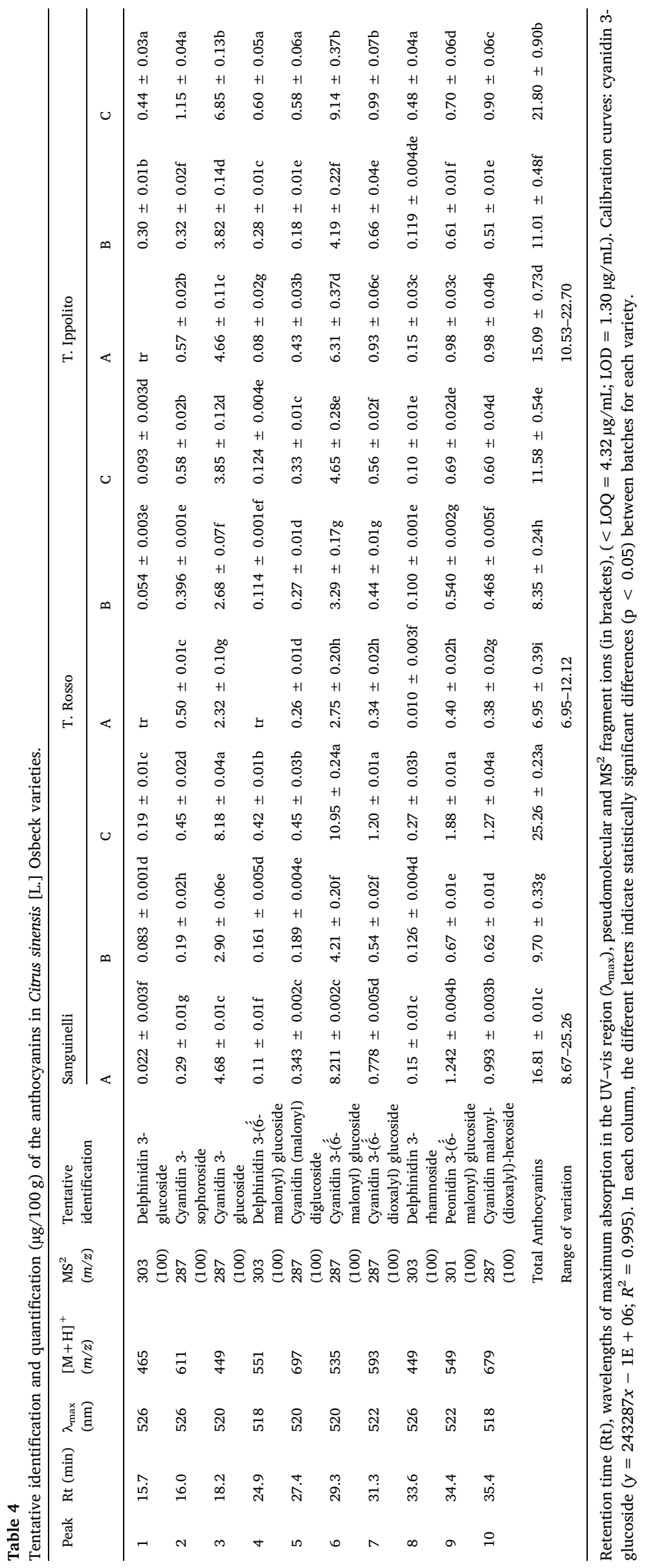


Table 5

Pulp colour parameters in Citrus sinensis [L.] Osbeck varieties.

\begin{tabular}{|c|c|c|c|c|c|c|}
\hline Variety & Batch & $\mathrm{L}^{*}$ & $a^{*}$ & $b^{*}$ & $C^{*}$ & h (hue) \\
\hline \multirow[t]{3}{*}{ Sanguinelli } & A & $46.96 \pm 1.30 c$ & $29.93 \pm 0.10 \mathrm{a}$ & $31.39 \pm 0.03 c$ & $43.38 \pm 0.61 b$ & $46.35 \pm 0.92 c$ \\
\hline & B & $41.29 \pm 0.06 \mathrm{~b}$ & $32.85 \pm 0.38 b$ & $28.42 \pm 0.69 b$ & $43.44 \pm 0.74 b$ & $40.86 \pm 0.37 b$ \\
\hline & $\mathrm{C}$ & $39.68 \pm 0.04 a$ & $34.54 \pm 0.07 c$ & $24.34 \pm 0.04 a$ & $42.25 \pm 0.05 a$ & $35.18 \pm 0.09 a$ \\
\hline Range of variation: & & $39.64-48.26$ & $29.83-34.61$ & $24.30-31.42$ & $42.20-44.24$ & $35.09-47.27$ \\
\hline \multirow[t]{3}{*}{ Tarocco Rosso } & A & $56.14 \pm 0.02 c$ & $20.70 \pm 0.93 a$ & $44.96 \pm 0.02 b$ & $49.49 \pm 0.02 b$ & $65.28 \pm 0.02 c$ \\
\hline & B & $49.65 \pm 0.01 \mathrm{a}$ & $26.93 \pm 0.01 c$ & $39.03 \pm 0.07 a$ & $47.42 \pm 0.06 \mathrm{a}$ & $55.40 \pm 0.05 a$ \\
\hline & $\mathrm{C}$ & $53.52 \pm 0.03 b$ & $23.33 \pm 0.02 b$ & $45.24 \pm 0.12 c$ & $50.90 \pm 0.12 c$ & $62.71 \pm 0.04 \mathrm{~b}$ \\
\hline Range of variation: & & $49.64-56.16$ & $21.63-26.94$ & $38.96-45.36$ & $47.36-49.51$ & $55.35-65.30$ \\
\hline \multirow[t]{3}{*}{ Tarocco Ippolito } & A & $49.32 \pm 2.62 c$ & $30.33 \pm 0.18 \mathrm{a}$ & $38.06 \pm 0.02 c$ & $48.68 \pm 3.87 c$ & $51.36 \pm 1.61 \mathrm{c}$ \\
\hline & B & $41.64 \pm 0.13 b$ & $32.07 \pm 1.51 \mathrm{~b}$ & $25.49 \pm 0.13 b$ & $40.28 \pm 0.18 b$ & $39.25 \pm 0.02 b$ \\
\hline & $\mathrm{C}$ & $36.85 \pm 0.02 \mathrm{a}$ & $33.86 \pm 0.02 c$ & $20.79 \pm 0.04 a$ & $39.73 \pm 0.02 \mathrm{a}$ & $31.55 \pm 0.06 a$ \\
\hline Range of variation: & & $36.83-51.94$ & $30.15-33.88$ & $20.75-38.08$ & $39.71-52.55$ & $31.49-52.97$ \\
\hline
\end{tabular}

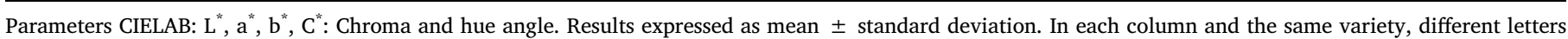
mean statistical differences per each sample $(p<0.05)$.

flavonoid. Regarding anthocyanins, ten different compounds were identified in the blood oranges, seven cyanidin derivatives and three delphinidin derivatives, the most abundant was cyanidin 3-(6"-malonylglucoside) and cyanidin 3-glucoside. All varieties analyzed (Sanguinelli, Tarocco Rosso and Tarocco Ippolito) presented high total anthocyanins content. Overall, blood orange varieties are good sources of bioactive compounds mainly vitamin $\mathrm{C}$.

The colour of the pulp of these oranges ranges from yellow-orange to reddish or more intense. Its coloration is due mainly to its content in carotenoids ( $\beta$-carotene), and to the presence of other water-soluble pigments of anthocyanic nature (mainly cyanidin 3-(6"-malonyl) glucoside and cyanidin 3-glucoside).

Finally, regarding colour determinations Sanguinelli and Tarocco Ippolito were the varieties with redder coloration in their pulp (higher $\mathrm{a}^{*}$ and lower $\mathrm{b}^{*}$ ), with the brightest colours (higher $\mathrm{C}^{*}$ ); while the Tarocco Rosso is the one variety with more yellow-orange coloration (higher $\mathrm{b}^{*}$ and lower $\mathrm{a}^{*}$ ) and high luminosity $\left(\mathrm{L}^{*}\right)$. The colour study demonstrated that there is no direct relationship between external and internal coloration; oranges could be found with a higher reddish colour in their peel whereas their pulp presents a yellow-orange colour,

Table 6

Peel colour parameters Citrus sinensis [L.] Osbeck varieties.

\begin{tabular}{|c|c|c|c|c|c|c|c|}
\hline Variety & Batch & Part of the fruit & $\mathrm{L}^{*}$ & $a^{*}$ & $b^{*}$ & $C^{*}$ & h (hue) \\
\hline \multirow[t]{9}{*}{ Sanguinelli } & \multirow[t]{3}{*}{ A } & Light & $59.09 \pm 7.98$ & $33.01 \pm 1.59$ & $53.41 \pm 13.67$ & $63.11 \pm 11.36$ & $57.39 \pm 7.53$ \\
\hline & & Dark & $57.87 \pm 4.11$ & $32.93 \pm 1.52$ & $51.38 \pm 7.44$ & $61.08 \pm 7.01$ & $57.15 \pm 2.67$ \\
\hline & & Base & $61.81 \pm 3.01$ & $32.00 \pm 1.62$ & $56.98 \pm 4.31$ & $65.40 \pm 3.60$ & $60.61 \pm 2.51$ \\
\hline & \multirow[t]{3}{*}{ B } & Light & $52.86 \pm 1.22$ & $34.67 \pm 0.23$ & $44.69 \pm 1.61$ & $56.57 \pm 1.37$ & $52.18 \pm 0.90$ \\
\hline & & Dark & $44.99 \pm 6.62$ & $32.79 \pm 3.09$ & $30.90 \pm 10.13$ & $45.25 \pm 9.26$ & $42.44 \pm 6.34$ \\
\hline & & Base & $46.01 \pm 1.21$ & $32.37 \pm 0.53$ & $34.85 \pm 1.15$ & $47.57 \pm 1.20$ & $47.11 \pm 0.48$ \\
\hline & \multirow[t]{3}{*}{$\mathrm{C}$} & Light & $57.90 \pm 10.22$ & $30.91 \pm 3.75$ & $51.73 \pm 15.20$ & $60.89 \pm 11.41$ & $57.86 \pm 10.23$ \\
\hline & & Dark & $41.91 \pm 4.24$ & $30.07 \pm 2.09$ & $26.06 \pm 7.04$ & $39.92 \pm 6.13$ & $40.30 \pm 5.93$ \\
\hline & & Base & $43.21 \pm 6.14$ & $32.13 \pm 2.41$ & $29.89 \pm 10.84$ & $44.16 \pm 9.26$ & $41.87 \pm 7.63$ \\
\hline Range of variation: & & & $37.07-68.12$ & $27.16-34.90$ & $19.02-67.08$ & $33.79-74.47$ & $34.24-64.94$ \\
\hline \multirow[t]{9}{*}{ Tarocco Rosso } & \multirow[t]{3}{*}{ A } & Light & $62.06 \pm 6.49$ & $34.64 \pm 4.26$ & $57.07 \pm 7.35$ & $67.02 \pm 4.50$ & $58.50 \pm 6.06$ \\
\hline & & Dark & $55.06 \pm 4.95$ & $34.38 \pm 1.83$ & $46.36 \pm 7.35$ & $57.90 \pm 5.15$ & $53.13 \pm 5.38$ \\
\hline & & Base & $62.91 \pm 2.35$ & $32.88 \pm 1.22$ & $58.64 \pm 3.56$ & $67.26 \pm 2.61$ & $60.66 \pm 2.30$ \\
\hline & \multirow[t]{3}{*}{ B } & Light & $50.19 \pm 4.70$ & $35.61 \pm 3.02$ & $41.26 \pm 7.62$ & $54.60 \pm 7.20$ & $48.92 \pm 4.02$ \\
\hline & & Dark & $50.39 \pm 1.27$ & $38.20 \pm 1.25$ & $41.58 \pm 2.42$ & $56.50 \pm 1.03$ & $47.40 \pm 2.56$ \\
\hline & & Base & $58.38 \pm 3.22$ & $35.54 \pm 2.37$ & $54.87 \pm 6.77$ & $65.45 \pm 6.01$ & $56.92 \pm 3.35$ \\
\hline & \multirow[t]{3}{*}{ C } & Light & $59.35 \pm 4.74$ & $33.60 \pm 2.84$ & $53.44 \pm 5.92$ & $63.27 \pm 3.80$ & $57.66 \pm 10.23$ \\
\hline & & Dark & $49.10 \pm 3.31$ & $35.67 \pm 1.91$ & $38.16 \pm 4.01$ & $52.34 \pm 1.71$ & $46.84 \pm 5.93$ \\
\hline & & Base & $60.58 \pm 3.42$ & $35.78 \pm 2.60$ & $57.25 \pm 4.87$ & $67.61 \pm 3.32$ & $57.90 \pm 7.63$ \\
\hline Range of variation: & & & $45.79-68.55$ & $30.76-38.90$ & $34.15-64.42$ & $47.40-71.52$ & $52.94-67.89$ \\
\hline \multirow[t]{9}{*}{ Tarocco Ippolito } & \multirow[t]{3}{*}{ A } & Light & $60.37 \pm 5.62$ & $33.41 \pm 1.46$ & $54.74 \pm 10.15$ & $64.34 \pm 8.05$ & $58.14 \pm 5.64$ \\
\hline & & Dark & $48.37 \pm 4.71$ & $36.26 \pm 1.08$ & $36.24 \pm 6.89$ & $51.45 \pm 4.54$ & $44.66 \pm 5.81$ \\
\hline & & Base & $59.87 \pm 0.76$ & $34.55 \pm 1.86$ & $53.56 \pm 0.80$ & $63.75 \pm 0.67$ & $57.18 \pm 1.72$ \\
\hline & \multirow[t]{3}{*}{ B } & Light & $61.95 \pm 5.53$ & $34.30 \pm 5.04$ & $59.23 \pm 8.01$ & $68.76 \pm 5.08$ & $59.64 \pm 6.65$ \\
\hline & & Dark & $54.69 \pm 9.27$ & $34.44 \pm 2.44$ & $45.39 \pm 16.59$ & $57.74 \pm 12.2$ & $51.26 \pm 11.07$ \\
\hline & & Base & $57.83 \pm 3.63$ & $37.03 \pm 1.30$ & $53.19 \pm 5.75$ & $64.84 \pm 5.36$ & $55.04 \pm 2.16$ \\
\hline & \multirow[t]{3}{*}{ C } & Light & $51.51 \pm 5.93$ & $37.34 \pm 1.76$ & $40.95 \pm 9.01$ & $55.74 \pm 5.60$ & $47.15 \pm 7.43$ \\
\hline & & Dark & $56.05 \pm 8.87$ & $36.55 \pm 1.91$ & $47.61 \pm 11.98$ & $60.46 \pm 8.25$ & $51.71 \pm 8.71$ \\
\hline & & Base & $60.47 \pm 3.28$ & $33.80 \pm 3.33$ & $55.75 \pm 3.49$ & $65.29 \pm 1.89$ & $58.73 \pm 3.87$ \\
\hline Range of variation: & & & $43.66-67.48$ & $29.26-39.10$ & $29.35-67.24$ & $46.91-73.84$ & $38.85-66.29$ \\
\hline
\end{tabular}

CIELAB Parameters: L", a*, b", C": Chroma and hue angle. 
as in the case of Tarocco Rosso.

\section{Acknowledgment}

Authors are grateful to OTRI UCM-ANECOOP S. Coop. (322-2015) project for financial support, and Dr. Ángel del Pino researcher for samples collection. The authors are also grateful to the Foundation for Science and Technology (FCT, Portugal) and FEDER under Programme PT2020 for financial support to CIMO (UID/AGR/00690/2013) and L. Barros contract; also to FEDER-Interreg España-Portugal programme for financial support through the project 0377_Iberphenol_6_E.

\section{References}

Abdelaali, S. B., Rodrigo, M. J., Saddoud, O., Zacarías, L., Hajlaoui, M. R., \& Mars, M. (2018). Carotenoids and colour diversity of traditional and emerging Tunisian orange cultivars (Citrus sinensis (L.) Osbeck). Scientia Horticulturae, 227, 296-304.

Agustí, M. (2003). Citricultura. Madrid, España: Mundi-Prensa52-53.

Alquézar, B., Rodrigo, M. J., \& Zacarias, L. (2008). Regulation of carotenoid biosynthesis during fruit maturation in the red-fleshed orange mutant Cara Cara. Phytochemistry, 69, 1997-2007.

Alquézar, B., Zacarías, L., \& Rodrigo, M. J. (2009). Molecular and functional characterization of a novel chromoplast-specific lycopene $\beta$-cyclase from citrus and its relation to lycopene accumulation. Journal of Experimental Botany, 60, 1783-11719.

Arena, E., Fallico, B., \& Maccarone, E. (2001). Evaluation of antioxidant capacity of blood orange juices as influenced by constituents, concentration process and storage. Food Chemistry, 74, 423-427.

Barbagallo, N. R., Palmeri, R., Fabiano, S., Rapisarda, P., \& Spagna, G. (2007). Characteristic of $\beta$-glucosidase from Sicilian blood oranges in relation to anthocyanin degradation. Enzyme and Microbial Technology, 41, 570-575.

Barreca, D., Gattuso, G., Laganà, G., Leuzzi, U., \& Bellocco, E. (2016). C- and O-glycosyl flavonoids in Sanguinello and Tarocco blood orange (Citrus sinensis (L.) Osbeck) juice: Identification and influence on antioxidant properties and cetylcholinesterase activity. Food Chemistry, 196, 619-627.

Berhow, M., Tisserat, B., Kanes, K., \& Vandercook, C. (1998). Survey of phenolics compounds produced in Citrus. Agricultural reserach service techonical bulletin. 1856. United States Department of Agriculture.

Braverman, J. S. (1933). The chemical composition of the orange. Hadar, 6, 62-65.

Choi, M. H., Kima, G. H., \& Leeb, H. S. (2002). Effects of ascorbic acid retention on juice colour and pigment stability in blood orange (Citrus sinensis) juice during refrigerated storage. Food Research International, 35, 753-759.

CIE, Commission internationale de l'éclairage. (2001). Technical report publication, 142. Continellaa, A., Pannitteria, C. La., Malfa, S., Leguab, P., Distefanoa, G., Nicolosia, E., \& Gentilea, A. (2018). Influence of different rootstocks on yield precocity and fruit quality of 'Tarocco Scirè' pigmented sweet orange. Scientia Horticulturae, 230, 62-67.

Destani, F., Cassano, A., Fazio, A., Vincken, J. P., \& Gabriele, B. (2013). Recovery and concentration of phenolic compounds in blood orange juice by membrane operations. Journal of Food Engineering, 117, 263-271.

Dugo, P., Mondello, L., Morabito, D., \& Dugo, G. (2003). Characterization of anthocyanin fraction of Sicilian blood orange juice by Micro-HPLC-ESI/MS. Journal of Agricultural and Food Chemistry, 51, 1373-1376.

Fabroni, S., Ballistreri, G., Amenta, M., \& Rapisarda, P. (2016). Anthocyanins in different Citrus species: An UHPLC-PDA-ESI/MSn-assisted qualitative and quantitative investigation. Journal of the Science of Food and Agriculture, 96, 4797-4808.

FAOSTAT. (2017). Base de datos disponible en: http://www.fao.org/faostat/en/\#data [Último acceso: 02/03/18].

Gonçalves, G. A., Soares, A. A., Correa, R. C. G., Barros, L., Haminiuk, C. W. I., Peralta, R. M., ... Bracht, A. (2017). Merlot grape pomace hydroalcoholic extract improves the oxidative and inflammatory states of rats with adjuvant-induced arthritis. Journal of Functional Foods, 33, 408-418.

Hillebrand, S., Schwarz, M., \& Winterhalter, P. (2004). Characterization of anthocyanins and pyranoanthocyanins from blood orange [Citrus sinensis (L.) Osbeck] juice. Journal of Agricultural and Food Chemistry, 52, 7331-7338.

Horwitz, W., \& Latimer, G. W. (2005). Official methods of analysis. Asociación de Químicos Analíticos Oficial Internacional AOAC (18th ed.). USA: AOAC International Association of Analytical Communities International.

Igual, M., García-Martínez, E., Camacho, M. M., \& Martínez-Navarrete, N. (2011). Changes in Flavonoid content of grapefruit juice caused by thermal treatment and storage. Innovative Food Science and Emerging Technologies, 12, 153-162.

Igual, M., García-Martínez, E., Camacho, M. M., \& Martínez-Navarrete, N. (2013). Jam processing and storage effects on $\beta$-carotene and flavonoids content in grapefruit. Journal of Functional Foods, 5, 736-744.

Kafkas, E., Ercisli, S., Kemal, K. N., Baydar, K., \& Yilmaz, H. (2009). Chemical composition of blood orange varieties from Turkey: A comparative study. Pharmacognosy Magazine, 5, 329-335.

Kelebek, H., Canbas, A., \& Selli, S. (2008). Determination of phenolic composition and antioxidant capacity of blood orange juices obtained from cvs. Moro and Sanguinello (Citrus sinensis (L.) Osbeck) grown in Turkey. Food Chemistry, 70, 1710-1716.

Lee, H. S., Carter, R. D., Barros, S. M., Dezman, D. J., \& Castle, W. S. (1990). Chemical characterization by liquid chromatography of moro blood orange juices. Journal of Food Composition and Analysis, 3, 9-19.

Lee, H. S. (2002). Characterization of major anthocyanins and the color of red-fleshed budd blood orange (Citrus sinensis). Journal of Agricultural and Food Chemistry, 50(5), 1243-1246.

Liang, L., Shao-Qian, C., \& Si-Yi, P. (2011). Thermal degradation kinetics of three kinds of representative anthocyanins obtained from blood orange. Agricultural Sciences in China, 10(4), 642-649.

Liu, Y., Liu, Q., \& Tao, N. (2006). Efficient isolation of RNA from fruit peel and pulp of ripening navel orange (Citrus sinensis Osbeck). Journal of Huazhong Agricultural University, 25, 300-304.

López-Bucio, J., Nieto-Jacobo, M. F., Ramírez-Rodríguez, V., \& Herrera-Estrella, L. (2000). Organic acid metabolism in plants: From adaptive physiology to transgenic varieties for cultivation in extreme soils. Plant Science, 160, 1-13.

MAPAMA. (2017). Ministerio de Agricultura y Pesca, Alimentación y Medio Ambiente. http://www.mapama.gob.es/es/estadistica/temas/estadisticas-agrarias/agricultura/ default.aspx [Última consulta 02/03/2018].

Meléndez-Martínez, A. J., Gómez-Robledo, L., Melgosa, M., Vicario, I. M., \& Heredia, F. J. (2011). Color of orange juices in relation to their carotenoid contents as assessed from different spectroscopic data. Journal of Food Composition and Analysis, 24(6), 837-884.

Olives Barba, A. I., Cámara, M., Sanchez Mata, M. C., Fernandez Ruiz, V., Saenz, Lopez, \& de Tejada, M. (2006). Aplication of UV-vis detection-HPLC method for a rapid determination of lycopene and b-carotene. Food Chemistry, 95, 328-336.

Rapisarda, P., Bellomo, S. E., \& Intrigliolo, F. (2001). Anthocyanins in blood orange: Composition and biological activity. Recent Research Development in Agricultural and Food Chemistry, 5, 217-230.

Rapisarda, P., Lo Bianco, M., Pannuzzo, P., \& Timpanaro, N. (2008). Effect of cold storage on vitamin $\mathrm{C}$, phenolics and antioxidant activity of five orange genotypes [Citrus sinensis (L.) Osbeck]. Postharvest Biology and Technology, 49, 348-354.

Regulation (EU) No 1169/2011 of the European Parliament and of the Council of 25 October 2011 on the provision of food information to consumers.

Sánchez-Mata, M. C., Cabrera Loera, R. D., Morales, P., Fernández-Ruiz, V., Cámara, M., Díez Marqués, C., ... Tardío, J. (2012). Wild vegetables of the Mediterranean area as valuable sources of bioactive compounds. Genetic Resources and Crops Evolution, 59, 431-443.

Shao-Qian, P., Si-Yi, Y., Xiao-Lian, F., \& Hong-Fei, F. (2010). Isolation and purification of anthocyanins from blood oranges by column chromatography CAO. Agricultural Sciences in China, 9(2), 207-215.

Vandercook, C. E. (1977). Organic acids. In S. Nagy, P. E. Shaw, \& M. L. Veldhuis (Eds.) Citrus science and technology (pp. 208-228). 